\title{
Submerged Cultivation of Ganoderma Iucidum Biomass in Stirred Tank Reactor
}

\author{
M. Berovič ${ }^{a, *}$ and M. Popovic ${ }^{b}$ \\ a Department of Chemical, Biochemical \& Ecology Engineering, \\ Faculty of Chemistry and Chemical Engineering, University of Ljubljana, \\ Večna pot 113, 1000 Ljubljana, Slovenia \\ bDepartment of Biotechnology, University of Applied Sciences, \\ Biotechnikum, Seestrasse 64, D-13347 Berlin, Germany
}

doi: 10.15255/CABEQ.2018.1371

Original scientific paper Received: May 1, 2018 Accepted: December 21, 2018

European isolated strain Ganoderma lucidum, its biomass formation, intracellular and extracellular polysaccharide production in batch and repeated fedbatch cultivation, were studied. The best fed batch results were obtained in the first feeding at $141 \mathrm{~h}$ at productivity of biomass $\mathrm{Px}=0.016 \mathrm{~g} \mathrm{~g}^{-1} \mathrm{~h}^{-1}$, intracellular $\mathrm{Pi}=0.010 \mathrm{~g} \mathrm{~g}^{-1} \mathrm{~h}^{-1}$, extracellular polysaccharides $\mathrm{Pe}=0.007 \mathrm{~g} \mathrm{~g}^{-1} \mathrm{~h}^{-1}$, and percent value of polysaccharides per cell dry weight $\mathrm{Pi} / \mathrm{x}=5.0 \%$ and $\mathrm{Pe} / \mathrm{x}=3.0 \%$. Although four feedings increased the amount of fungal biomass by $42.66 \%$, productivities of fungal polysaccharides $\mathrm{Pi}=0.010 \mathrm{~g} \mathrm{~g}^{-1} \mathrm{~L}^{-1}$ and $\mathrm{Pe}=0.011 \mathrm{~g} \mathrm{~g}^{-1} \mathrm{~L}^{-1}$ showed that at the fourth feeding, the biomass was already exhausted and polysaccharide production was reduced. Therefore, $210 \mathrm{~h}$ batch cultivation with $\mathrm{Px}=0.095 \mathrm{~g} \mathrm{~g}^{-1} \mathrm{~L}^{-1}, \mathrm{Pi}=0.078 \mathrm{~g} \mathrm{~g}^{-1} \mathrm{~L}^{-1}$ at $\mathrm{Pi} / \mathrm{x}=33 \%$ and extracellular polysaccharides $\mathrm{Pe}=0.095 \mathrm{~g} \mathrm{~g}^{-1} \mathrm{~L}^{-1}$ at $\mathrm{Pe} / \mathrm{x}=6.8 \%$, was found to be the best mode for $G$. $l u$ cidum fungal biomass and polysaccharides production. Non-Newtonian cultivation broth rheology was found to be influenced entirely by the concentration and morphology of the biomass.

Keywords:

Ganoderma lucidum, batch fermentation, repeated fed batch, stirred tank reactor, fungal polysaccharides, hydrodynamic behaviour

\section{Introduction}

In the last decades, basidiomycetes of various Ganoderma spp. and their wide range of pharmaceutically interesting products are one of the most attractive groups of natural products in Asia and North America. Most of the research has been related to Ganoderma lucidum, a recognised traditional remedy used in Chinese and Japanese traditional medicine. In Asian traditional medicine, the fruiting body of Ganoderma lucidum, called Ling-Zhi in Chinese and Reishi in Japanese, has been used for treatment of a series of diseases, including hepatitis, arthritis, nephritis, bronchitis, asthma, arteriosclerosis, hypertension, cancers and gastric ulcer ${ }^{1-3}$. Several investigations report on its antiallergenic constituents $^{4}$, immunomodulatory action ${ }^{5}$ and treatment of HIV infections, antitumor ${ }^{6}$ and cardiovascular effects $^{7}$, liver protection and detoxification, and effects on nervous system ${ }^{8}$.

Pharmaceutically active compounds from $G$. lucidum include triterpenoids, proteins, steroids, alkaloids, nucleotides, lactones, and fatty acids. Polysaccharides (especially $\beta$-D-glucanes) have been

"Corresponding author: Tel. + 38640636943

E-mail: Marin.Berovic@fkkt.uni-lj.si recognised as an effective anti-cancer drug ${ }^{9}$. In Ganoderma polysaccharide research, special attention was paid to their immunomodulatory effects ${ }^{10,11}$.

For a large-scale production of medicinal fungi biomass and their active pharmaceutical compounds, antitumor, and anticancer acting polysaccharides, submerged cultivation is one of the most reliable technologies. The mechanism of fungal growth in nature is strongly connected with pasting the fungal tips on the solid matrix. For this purpose, large amounts of sticky fungal polysaccharides are produced and accumulated on the tip of young hyphae cells. This jelly-like material serves as the sticky plaster for anchoring the fungal tips onto the solid matrix. The polysaccharide gel serves also as the matrix for the transfer of cellulolytic and xylolytic enzymes on the surface of cellulose materials. On solid matrixes, fungal mycelia also use polysaccharide gels as a basis for moving on the surface.

For fungal biomass growth in submerged cultivations, accumulation of polysaccharides is not necessary. However, in high mixing shear fields, polysaccharides are secreted at the tips of young fungal hyphae cells. This gel-like material enters the liquid substrate where it increases the pseudoplasticity of the submerged cultivation broth. Increased pseudo- 
plasticity of the cultivation broth rapidly influences the reduction of mass and heat transfer. When the oxygen transfer is limited, higher agitation and more intensive aeration are required to increase the dissolved oxygen concentration in the media. Increased shear forces occur by increasing the oxygen transfer in the media, which strongly influences the fungal disintegration, resulting in growth damage.

Modern biotechnological cultivations in bioreactors, especially with submerged liquid substrate cultivation have been developed previously ${ }^{12-15}$. The quality and content of physiologically active substances vary from strain to strain, and also depending on the location, culture conditions ${ }^{14}$, growth stage of the fungus ${ }^{17}$ ), processing procedures, and formulation preparation of $\beta-1-3-D, \beta-1-4-D$ and $\beta$-1-6-D glucans ${ }^{18}$.

In general, for high amounts of G. lucidum biomass and polysaccharide production, stirred tank reactors (STR) are still the most used types on the industrial scale ${ }^{17}$. The main disadvantages of using STRs are the high energy-consumption and maintenance costs. In addition, changes in rheology from Newtonian to non-Newtonian conditions appear over the time of cultivation, due to the secretion of the fungal polysaccharides, which results in pseudoplastic behaviour of the culture broth. STRs are very suitable, especially in processes of cultivation broth that represent great reductions of hydrodynamic conditions, which have significant influence on the mass transfer ${ }^{21}$.

Submerged cultivation of large amounts of fungal biomass is the most widely used alternative to farming production ${ }^{19,12,24,25,28}$. Besides optimization of process rheology and mass transport, an efficient cultivation process combines the production of fungal biomass and secretion of fungal polysaccharides in high shear fields. However, few investigations have considered the optimization of some other cultivation parameters, such as rate of agitation ${ }^{20}, \mathrm{pH}^{21}$, inoculation density ${ }^{26}$, temperature, and medium composition $^{22,27}$. According to Zhu et al. ${ }^{28}$, roughly half of the studies on G. lucidum submerged cultivation were performed in Erlenmeyer flasks, but not in bioreactors.

Batch cultivation has been found to be the simplest and most often used and reported technique $^{12,23,28}$. A fed-batch process for simultaneous production of ganoderic acids and polysaccharides by G. lucidum has been described by Tang and Zhong ${ }^{23}$. Ganoderic acids production remarkably improved by the pulse feeding of lactose, when its residual concentration was between 10 and $5 \mathrm{~g} \mathrm{~L}^{-1}$. Effects of oxygen supply and lactose feeding on fed-batch submerged culture of G. lucidum have also been investigated ${ }^{23,28,29}$. A higher volumetric oxygen transfer coefficient $\left(k_{\mathrm{L}} a\right)$ value led to a high- er biomass density and a higher productivity of both intracellular polysaccharides and ganoderic acids. In a stirred bioreactor, at an initial $k_{\mathrm{L}} a$ of $78.2 \mathrm{~h}^{-1}$, obtained were a maximal cell concentration of 15.6 $\mathrm{g} \mathrm{L}^{-1}$ by dry weight, and a maximal intracellular polysaccharides production of $2.2 \mathrm{~g} \mathrm{~L}^{-1}$. An increase in initial $k_{\mathrm{L}} a$ from $16.4 \mathrm{~h}^{-1}$ to $96.0 \mathrm{~h}^{-1}$ led to a 1.8 fold higher production of ganoderic acids. Tang et $a l .{ }^{22,23}$ achieved a significant synergistic enhancement of ganoderic acids accumulation, up to 754.6 $\mathrm{mg} \mathrm{L}^{-1}$, which was the highest reported in the submerged cultivation of G. lucidum.

Submerged fungal biomass cultivation is a process that produces significant amounts of extracellular fungal polysaccharides. Contrary to most of the publications using various Asiatic G. lucidum sp. strains, in this study, the engineering aspects of the original European strain and substrate were investigated.

The aim of present research was to find out which kind of mode of operation is more suitable as a platform for large scale production of G. Lucidum biomass and fungal pharmaceutica active polysaccharides.

\section{Materials and methods}

\section{Microorganism}

A Slovenian G. lucidum strain Ga. 14 (BFWS,1996) (Fig. 1), was used in all of the experiments. The strain was cryopreserved ${ }^{12}$ and maintained on Petri dishes on potato dextrose agar (PDA) (Difco, USA) prepared by dissolving $39 \mathrm{~g}$ of dehydrated agar in $1 \mathrm{~L}$ distilled water at $T=24{ }^{\circ} \mathrm{C}$. It was maintained at $24^{\circ} \mathrm{C}$, and re-inoculated every 3 weeks to maintain its viability and activity ${ }^{12}$.

\section{Cultivation of inoculum}

The inoculum consisted of five $1-\mathrm{cm}^{2}$ cuts of a 7-day-old culture cultivated on PDA (Difco, USA) at $24^{\circ} \mathrm{C}^{12}$. After the inoculation of $100 \mathrm{~mL}$ of liquid substrate, the biomass was cultivated in $250-\mathrm{mL} \mathrm{Er-}$ lenmeyer flasks on a rotary shaker for 14 days $(N=$ $100 \mathrm{rpm} ; T=30^{\circ} \mathrm{C}$ ), and transferred to a bioreactor in its exponential growth phase ${ }^{12}$.

\section{Submerged cultivation}

\section{Substrate}

Preliminary studies including substrate optimization using Plackett-Burman method have already been mentioned ${ }^{12}$. For the preparation of the cultivation medium, $3.0 \mathrm{~kg}$ of peeled and cut potatoes were cooked in $2 \mathrm{~L}$ demineralised water, the mash was filtered, and the filtrate was added to $10 \mathrm{~L}$ de- 


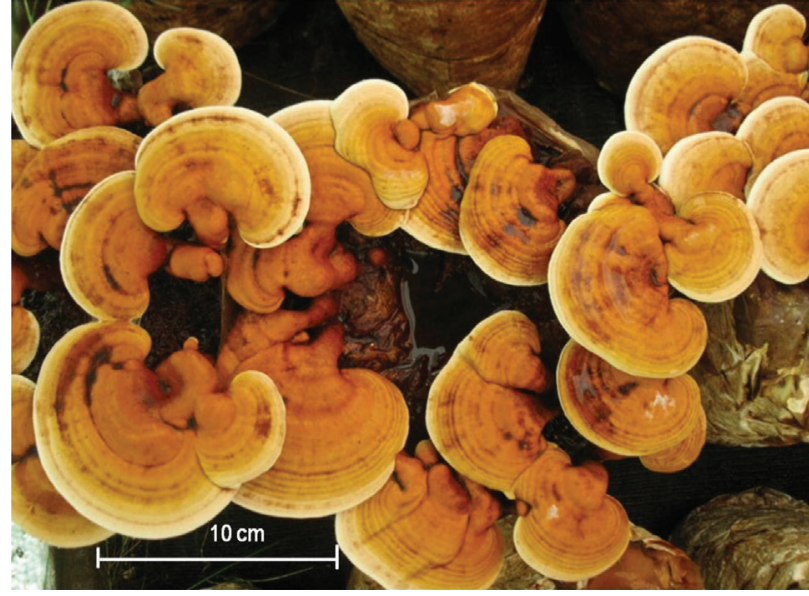

Fig. 1 - Ganoderma lucidum in nature (Photo A. Gregori)

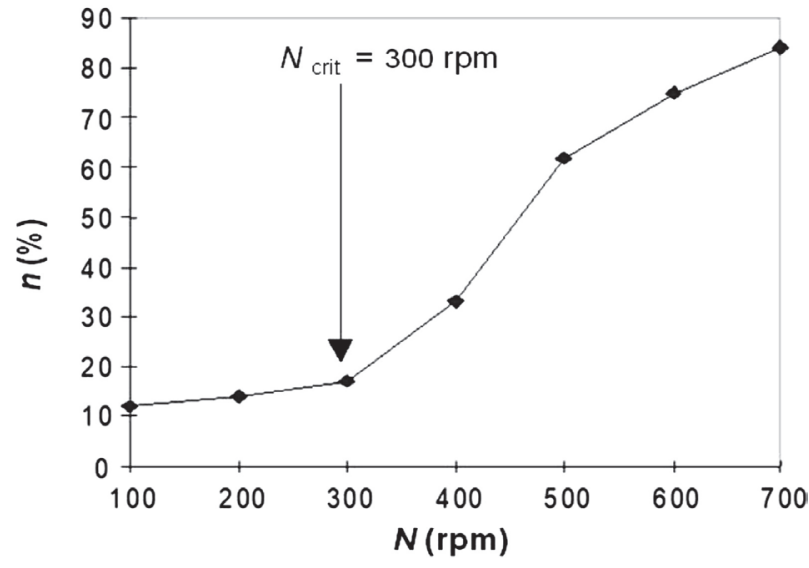

Fig. 2 - Critical agitation speed for hyphae damage in Ganoderma lucidum cultivation in stirred tank reactor $n(\%)$ percentage of hyphae damage

mineralised water. Upon cooling and filtration, 4.5 $\mathrm{L}$ of the mash filtrate was diluted with demineralised water up to $10 \mathrm{~L}$. Twenty grams of glucose per litre and $2 \%(\mathrm{v} / \mathrm{v})$ of olive oil were added, and $\mathrm{pH}$ was adjusted with $0.5 \mathrm{M}$ sulphuric acid to 5.8. Substrate was sterilised in-situ in the bioreactor for $20 \min \left(T=121{ }^{\circ} \mathrm{C}\right.$ at $\left.p=1.2 \cdot 10^{5} \mathrm{~Pa}\right)$ at a stirrer speed of $N=100 \mathrm{rpm}$.

\section{Bioreactor}

All the experiments were performed in a $10-\mathrm{L}$ stirred tank reactor (Bioengineering AG, Switzerland) mixed by three Ruston turbines $(d=60 \mathrm{~mm})$ with four baffles and standard tank configuration. Oxygen partial pressure was measured by polarographic sensor IL MGF 509, the redox potential by Ingold $\mathrm{Pt} 4865$, and the $\mathrm{pH}$ by Ingold $465-35 \mathrm{k} 1$ sensor. Inoculum in concentration of $17 \%$ (wet weight) was used. All experiments were performed at the aeration rate of $Q_{\mathrm{g}}=1.0 \mathrm{~L}$ air/L substrate/ min. A $20 \%$ decrease in cultivation broth volume caused by evaporation and sampling was taken into account in all experiments. Cultivation temperature was $T=30{ }^{\circ} \mathrm{C}$.

\section{Mixing}

In previous experiments, the critical mixing rate was determined. Each cultivation experiment was performed at constant mixing rate in the range from 100 to $700 \mathrm{rpm}$. A ten-millilitre biomass sample was taken every $24 \mathrm{~h}$, and the percentage of damaged hyphae, $n(\%)$ was determined ${ }^{12}$ from optical microscope photos (magnification 100) (Fig. 2).

\section{Cultivation of fungal biomass}

Cultivation conditions were as follows: temperature of cultivation $30{ }^{\circ} \mathrm{C}$; mixing rate $300 \mathrm{rpm}$; aeration $1 \mathrm{vvm}$; average measured values of $\mathrm{pH} 5.8$ to 4.2 ; oxygen partial pressure $70-80 \%$, and redox potential 300 to $400 \mathrm{mV}$. Repeated fed batch cultivation started at the same conditions as the batch, first feeding started at $141 \mathrm{~h}$, the second feeding started at $367 \mathrm{~h}$, the third feeding at $573 \mathrm{~h}$, and finally, the fourth feeding started at $902 \mathrm{~h}$ of fermentation. In each feeding, 1/3 of the cultivation broth was replaced with new fresh substrate.

\section{Analytical methods}

\section{Biomass}

Ten millilitres of the submerged cultivation broth was filtered, and the biomass on the filter was washed 3 times with distilled water, and after drying for $24 \mathrm{~h}$ at $105{ }^{\circ} \mathrm{C}$, determined gravimetrically.

\section{Extraction and fractionation of polysaccharides}

Polysaccharides were determined by disintegration and extraction of $15 \mathrm{~g}$ of fungal pellet biomass sample with boiling water for $5 \mathrm{~h}$. The suspension was filtered to remove the insoluble matter, and the polysaccharides were then precipitated by adding the 3 -fold volume of $96 \%$ ethanol. The precipitate was then freeze-dried. ${ }^{7}$

\section{Extracellular polysaccharides}

For determination of extracellular polysaccharides, $20 \mathrm{~mL}$ of the broth sample was filtered, filtrate was diluted with $100 \mathrm{~mL}$ of demineralized water, precipitated by adding 3-fold volume of $96 \%$ ethanol, and left for $12 \mathrm{~h}$ at $0-4{ }^{\circ} \mathrm{C}$. Polysaccharides were washed with $2 \times 20 \mathrm{~mL}$ acetone and ether.

\section{Intracellular polysaccharides}

Filter cake from the previous procedure was used for determination of intracellular cell wall polysaccharides. Filter cake was cooked with 10 
$\mathrm{mL}$ of distilled water for $3 \mathrm{~h}$ at $100{ }^{\circ} \mathrm{C}$. Polysaccharides were then precipitated with 3 -fold volume of $96 \%$ ethanol, and solution was left for $12 \mathrm{~h}$ at $0-4$ ${ }^{\circ} \mathrm{C}$. The filter cake was washed with $2 \times 20 \mathrm{~mL}$ acetone and ethyl ether, dried for $24 \mathrm{~h}$ in a drying chamber at $105^{\circ} \mathrm{C}$, and weighed.

\section{Volumetric oxygen transport coefficient}

Volumetric oxygen transport coefficient in cultivation broth was measured by dynamic method ${ }^{28}$ using a polarographic electrode MFG 509 with IL Amplifier Type 531 (Industrial Lab, Switzerland). Measurement were corrected according to electrode response time $(\tau=22 \mathrm{~s})$, gas and liquid dynamics ${ }^{30}$.

\section{Rheological measurements}

Rheological measurements of flow behaviour and fluid consistency index were performed using a Rheotest 3 viscometer in a double cylinder configuration (2VEB MLW, Pruferate-Werk, Medingen, Germany). A rotating cylinder $(d=37.7 \mathrm{~mm}$ inner diameter) and measuring cell (D040.39 mm outer diameter) were used. The rheological properties were characterized by the Ostwald-de Waele power law model $^{31}$.

\section{Microscopy}

Cell morphology was examined with light microscope Axioscope, Zeiss (Fig. 6b). The SEM images were taken using a field-emission electronsource SEM JEOL 7600F, Tokyo, Japan, operated at $15 \mathrm{kV}$ (Fig. 6a). Macro-photos were taken by Nikon XF10 (Fig. 7).

\section{Statistics}

All of the cultivation experiments were performed at least in three runs. The results were analyzed for statistical significance by one-way analysis of variance (ANOVA) test using the Statistical Package of the Social Science (SPSS) version 11.0 (SPSS Inc., Chicago, IL, USA). Statistical significance of the test effects was evaluated at $p<0.05$.

\section{Results and discussion}

\section{Batch mode of fermentation}

In the first part, the batch mode, i.e., the simplest and the most used process for submerged cultivation of G. lucidum cultivation, was studied. The cultivation proceeded for $210 \mathrm{~h}$. Productivity of biomass was $\mathrm{Px}=0.095 \mathrm{~g} \mathrm{~g}^{-1} \mathrm{~L}^{-1}$, while the productivity of intracellular $\mathrm{Pi}=0.078 \mathrm{~g} \mathrm{~g}^{-1} \mathrm{~L}^{-1}$ at $\mathrm{Pi} / \mathrm{x}=33$ $\%$ of percent value of polysaccharides per cell dry weight and extracellular polysaccharides $\mathrm{Pe}=0.095$ $\mathrm{g} \mathrm{g}^{-1} \mathrm{~L}^{-1}$ at $\mathrm{Pe} / \mathrm{x}=6.8 \%$.

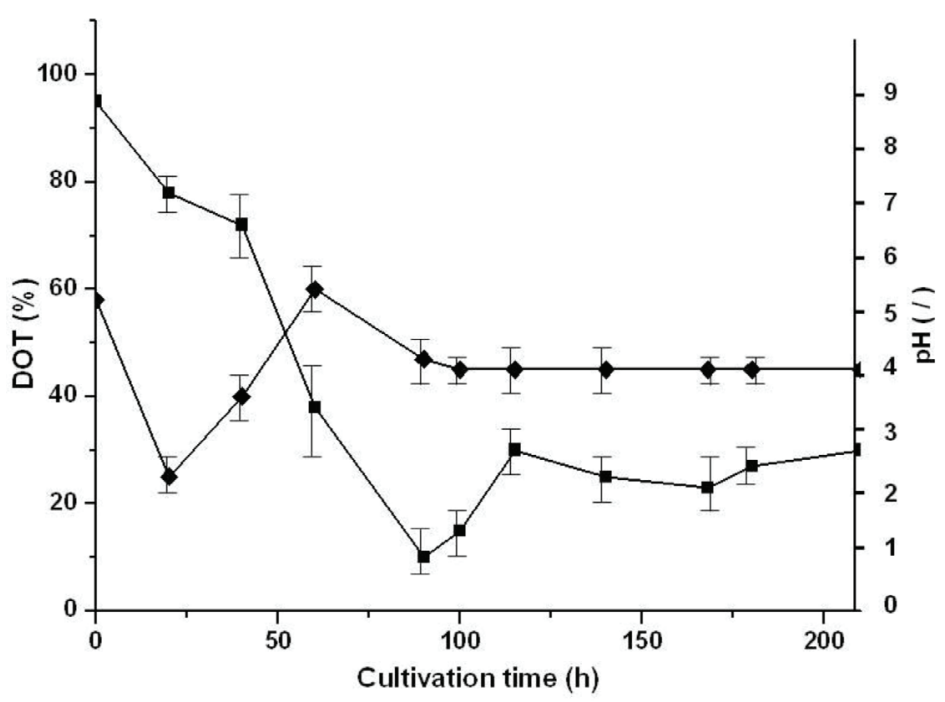

Fig. 3 - Batch cultivation of Ganoderma lucidum $\bullet$ pH; dissolved oxygen tension (DOT) expressed in percentage of saturation pressure

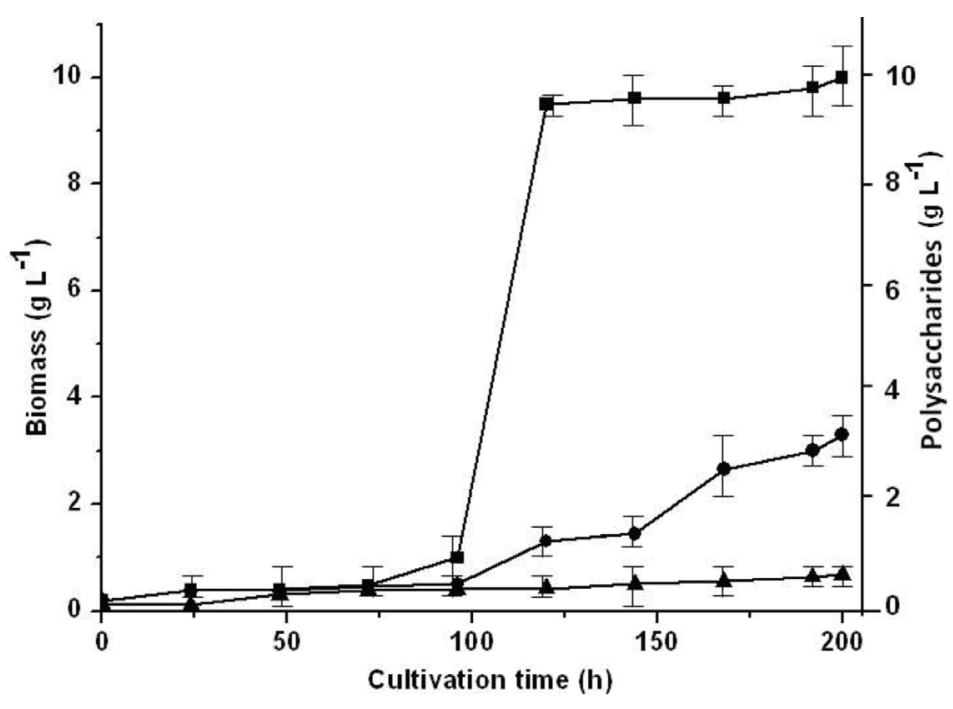

Fig. 4 - Batch cultivation of Ganoderma lucidum $\mathbf{n}$ biomass; - intracellular; $\boldsymbol{\Delta}$ extracellular polysaccharides

Rheologically, G. lucidum cultivation broth was characterized by biomass concentration and its physiology state. The secretion of ganoderic acids that had already started from 12 to $24 \mathrm{~h}$, influenced $\mathrm{pH}$ to decrease to 2.5. In further cultivation, the $\mathrm{pH}$ increased to 6 and then stabilized at 4.5. Microbial growth may cause marked changes in the $\mathrm{pH}$ of a substrate. Acid production, due to incomplete oxidation of the substrate or uptake of ammonium ions, could influence the decrease in $\mathrm{pH}$, whereas the release of ammonia by deamination of urea or other amines will increase the $\mathrm{pH}$ (Fig. 3).

In this first part up to $18 \mathrm{~h}$, microbial growth was characterized by hyphae forms mycelia and low biomass concentration of up to $2.5 \pm 0.04 \mathrm{~g} \mathrm{~L}^{-1}$, where typical Newtonian behaviour with flow behaviour index $n=1.00-0.95 \pm 0.02$ was indicated. 


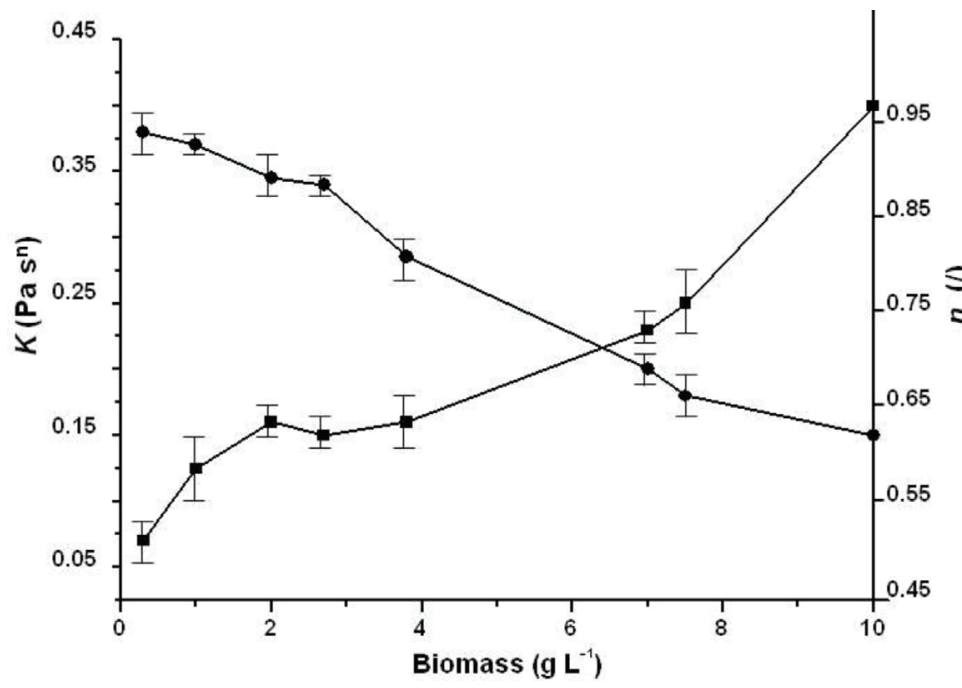

Fig. 5 - Changes in flow behaviour index $n(\bullet)$ and fluid consistency index $K(\mathbf{\square})$ influenced by the increase in biomass concentration, $X$

From 90 to $143 \mathrm{~h}$, the growth turned from hyphae to spherical microbial pellets $\left(d_{p}=0.3-0.8 \cdot 10^{-3} \mathrm{~m}\right)$ formed by sticking the tips of hyphae in the shear field, and biomass concentration from $3.25 \mathrm{~g} \mathrm{~L}^{-1}$ to $10.0 \pm 0.5 \mathrm{~g} \mathrm{~L}^{-1}$ was indicated (Fig. 4).

In the exponential growth phase, high oxygen consumption was detected (Fig. 3), and at $90 \mathrm{~h}$, the dissolved oxygen tension decreased to $10 \%$ of saturation followed also by intensive intracellular (3.30 $\left.\mathrm{g} \mathrm{L}^{-1}\right)$ and extracellular polysaccharides (0.68 $\mathrm{g} \mathrm{L}^{-1}$ ) production (Fig. 4). In this period, significant non-Newtonian pseudoplastic behaviour of the cultivation broth was detected. The flow behaviour index was drastically reduced to $n=0.68 \pm 0.05$, and the fluid consistency index $K$ increased up to $0.380 \pm 0.04 \operatorname{Pas}^{n}$ (Fig. 5). Increasing biomass and pseudoplasticity of cultivation broth strongly influenced the $k_{\mathrm{L}} a$ coefficient that was reduced from $250.0 \mathrm{~h}^{-1}$ to final $58.5 \mathrm{~h}^{-1}$ at the end of the cultivation at $210 \mathrm{~h}$.

In the range of applicable shear rates, rheological behaviour of the cultivation broth can be characterised by Ostwald-de Waele model. The changes in the flow behaviour index $n$ and consistency index $K$ with biomass concentration can be observed in Fig. 5. Time change of the rheological properties during the presented biomass cultivations depended on morphology, biomass concentration, and production of sticky polysaccharides on the tip of the hyphae (Fig. 6a). The polysaccharides were turbine sucked and transferred into the cultivation broth through the created shear field effected by Rushton turbine, Fig. 6b.

Rheological behaviour of the cultivation media is strongly related to the growth stage of the fungal biomass. Although the cultivation broth from 18 to $210 \mathrm{~h}$ expressed a significant pseudoplastic non-Newtonian flow behaviour, the viscosity of the filtrate in all samples of this period was low with $(2.00 \pm 0.08) \cdot 10^{-3} \mathrm{~Pa} \mathrm{~s}$, and did not change significantly over the cultivation time.

In the exponential growth phase, intensive foaming was detected. The foam was produced by the fungal biomass floating on the liquid surface in the reactor. It was controlled using the contact sensor through addition of an emulsion of polypropylene glycol in silicone oil. In the parts below the contact sensor and in the the head space parts, stuck pellets started growing.
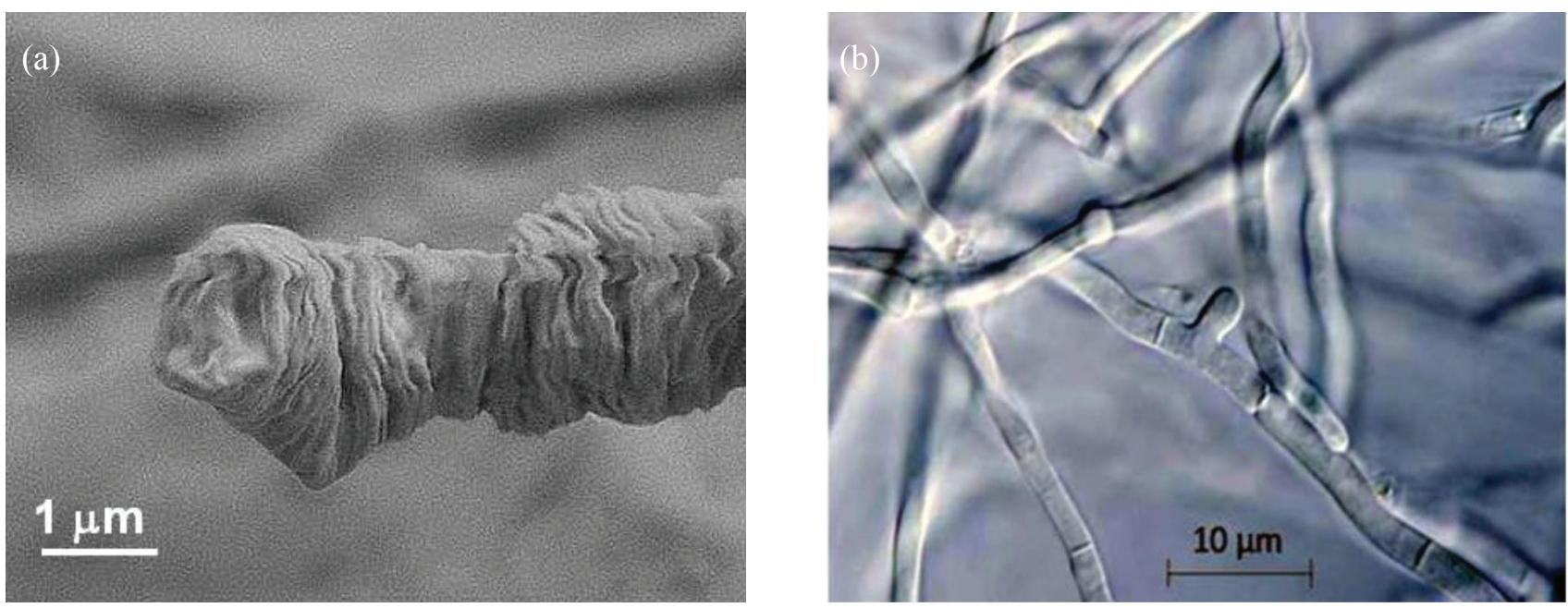

Fig. 6 - (a) Accumulation of external fungal polysaccharides on the tip of hyphae in nature (left); (b) naked and external polysaccharides free hyphae in submerged Ganoderma lucidum cultivation (right) 

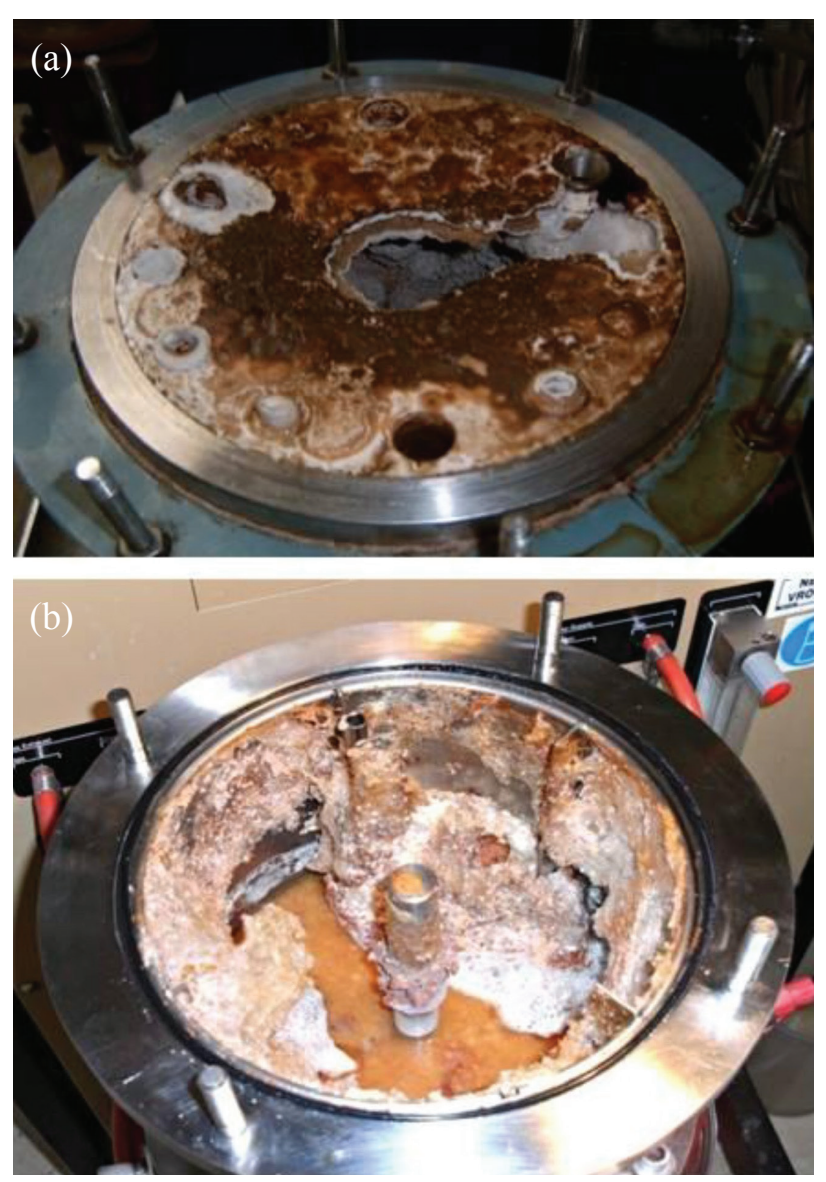

Fig. 7 - (a) Overgrown head space (left), (b) overgrown stirrer and sensors in stirred tank reactor (right)

In further cultivations, fungal biomass in the headspace intensively grew covering the tips of the sensors, including the foam detector (Fig. 7). Consequently, excess of antifoam agent was added and the pseudoplasticity of the broth drastically increased. Dissolved oxygen tension dropped to $3.2 \pm 0.2 \%$ of saturation and higher mixing intensity was required. Concerning the preliminary experiments for the applied Rushton turbine as described previously, the stirring rate was not increased above the critical value of $300 \mathrm{rpm}$, in order to prevent hyphae damage (Fig. 7).

\section{Repeated fed batch cultivation}

In the second part of the experiment, fresh substrate feeding at various time intervals in a repeated fed batch process was introduced (Fig. 8). In the further cultivation, four feedings were applied. After exhausting the substrate, with each feeding, 1/3 of the total volume was replaced with a fresh substrate. The first feeding of the substrate took place at $141 \mathrm{~h}$. In the first feeding, the biomass was diluted from 7.56 to $3.08 \mathrm{~g} \mathrm{~L}^{-1}$, intracellular polysaccharide dropped from 3.00 to $1.30 \mathrm{~g} \mathrm{~L}^{-1}$, and extracellular concentration changed from 0.73 to $0.32 \mathrm{~g} \mathrm{~L}^{-1}$. Productivity of biomass in this part was $\mathrm{Px}=0.019$ $\mathrm{g} \mathrm{g}^{-1} \mathrm{~L}^{-1}$, while the productivity of intracellular $\mathrm{Pi}=0.015 \mathrm{~g} \mathrm{~g}^{-1} \mathrm{~L}^{-1}$ at $\mathrm{Pi} / \mathrm{x}=5.0 \%$ of percent value of polysaccharides per cell dry weight and extracellular polysaccharides $\mathrm{Pe}=0.014 \mathrm{~g} \mathrm{~g}^{-1} \mathrm{~L}^{-1}$ at $\mathrm{Pe} / \mathrm{x}=$ $3.0 \%$.

After the second feeding at $373 \mathrm{~h}$, the biomass dropped from 10.16 to $6.44 \mathrm{~g} \mathrm{~L}^{-1}$, intracellular polysaccharides from 2.45 to $1.60 \mathrm{~g} \mathrm{~L}^{-1}$, and extracellular from 0.60 to $0.40 \mathrm{~g} \mathrm{~L}^{-1}$ at $\mathrm{Px}=0.014 \mathrm{~g} \mathrm{~g}^{-1} \mathrm{~L}^{-1}$ at the productivity of intracellular $\mathrm{Pi}=0.010 \mathrm{~g} \mathrm{~g}^{-1} \mathrm{~L}^{-1}$ and $\mathrm{Pe}=0.0087 \mathrm{~g} \mathrm{~g}^{-1} \mathrm{~L}^{-1} \mathrm{Pi} / \mathrm{x}=11.32 \%$ and $\mathrm{Pe} / \mathrm{x}=$ $5.06 \%$

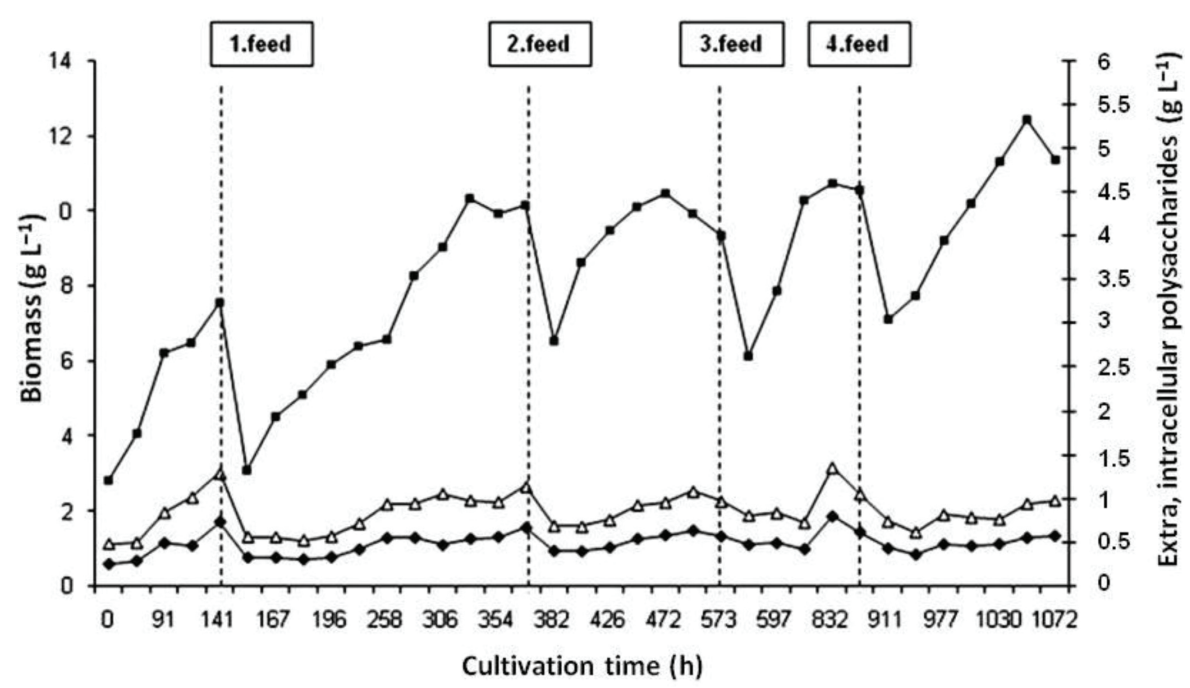

Fig. 8 - Production of biomass and fungal polysaccharides in fed-batch cultivation, feeding at 141, 367, 573, and $902 \mathrm{~h}$; biomass; $\Delta$ intracellular; extracellular polysaccharides 
The third feeding was at $573 \mathrm{~h}$. By the third feeding, the values of all three measured parameters declined, biomass to $6.22 \mathrm{~g} \mathrm{~L}^{-1}$, intracellular polysaccharides to $0.82 \mathrm{~g} \mathrm{~L}^{-1}$, and extracellular to 0.5 $\mathrm{g} \mathrm{L}^{-1}$, at $\mathrm{Px}=0.0090 \mathrm{~g} \mathrm{~g}^{-1} \mathrm{~L}^{-1}$ at the productivity of intracellular $\mathrm{Pi}=0.010 \mathrm{~g} \mathrm{~g}^{-1} \mathrm{~L}^{-1}$ and $\mathrm{Pe}=0.010 \mathrm{~g} \mathrm{~g}^{-1}$ $\mathrm{L}^{-1}$, and at $\mathrm{Pi} / \mathrm{x}=12.72 \%$ and $\mathrm{Pe} / \mathrm{x}=7.27 \%$.

The last, fourth feeding was performed at 904 h. It lowered the biomass from 10.57 to $7.11 \mathrm{~g} \mathrm{~L}^{-1}$ as well as the level of polysaccharides from 1.07 to $0.80 \mathrm{~g} \mathrm{~L}^{-1}$ for intracellular and from 0.62 to 0.43 $\mathrm{g} \mathrm{L}^{-1}$ for extracellular polysaccharides at $\mathrm{Px}=0.010$ $\mathrm{g} \mathrm{g} \mathrm{g}^{-1} \mathrm{~L}^{-1}$ at the productivity of intracellular $\mathrm{Pi}=$ $0.010 \mathrm{~g} \mathrm{~g} \mathrm{~g}^{-1} \mathrm{~L}^{-1}$ and $\mathrm{Pe}=0.011 \mathrm{~g} \mathrm{~g}^{-1} \mathrm{~L}^{-1}$. After the fourth feeding, the cultivation proceeded to $1072 \mathrm{~h}$, and finally $12.40 \mathrm{~g} \mathrm{~L}^{-1}$ of biomass, $1.0 \mathrm{~g} \mathrm{~L}^{-1}$ of intracellular polysaccharides and $0.58 \mathrm{~g} \mathrm{~L}^{-1}$ of extracellular polysaccharides were obtained. In the last $98 \mathrm{~h}$, at $\mathrm{Pi} / \mathrm{x}=8.06 \%$ and $\mathrm{Pe} / \mathrm{x}=6.8 \%$.

\section{Conclusions}

Cultivation of G. lucidum submerged cultivation showed significant changes in rheological properties of the cultivation broth. Shear field of the radial stirrer slipped the external fungal polysaccharides from the tips of hyphae and sucked them into the cultivation broth, which influenced the change from Newtonian to the pseudoplasticity character of the broth. Non-Newtonian properties of the cultivation broth depended entirely on the concentration and morphology of the biomass, since the liquid phase was a low-viscosity Newtonian fluid.

Fed batch results lead to the conclusion that the best results in biomass and polysaccharide production were obtained in the first batch part $(\mathrm{Px}=0.019$ $\left.\mathrm{g} \mathrm{g}^{-1} \mathrm{~h}^{-1}, \mathrm{Pi}=0.012 \mathrm{~g} \mathrm{~g}^{-1} \mathrm{~h}^{-1}, \mathrm{Pe}=0.009 \mathrm{~g} \mathrm{~g}^{-1} \mathrm{~h}^{-1}\right)$, while from the feeding procedure, the best results $\mathrm{Px}=0.016 \mathrm{~g} \mathrm{~g}^{-1} \mathrm{~h}^{-1}, \mathrm{Pi}=0.010 \mathrm{~g} \mathrm{~g}^{-1} \mathrm{~h}^{-1}, \mathrm{Pe}=0.007$ $\mathrm{g} \mathrm{g}^{-1} \mathrm{~h}^{-1}$ were obtained at the first feeding. Although four feedings enabled the increasing in fungal biomass by $42.66 \%, \mathrm{Pi} / \mathrm{x}=8.06 \%$ and $\mathrm{Pe} / \mathrm{x}=6.8 \%$ were low, which indicates low productivity of fungal polysaccharides $\mathrm{Pi}=0.010 \mathrm{~g} \mathrm{~g}^{-1} \mathrm{~L}^{-1}$ and $\mathrm{Pe}=$ $0.011 \mathrm{~g} \mathrm{~g}^{-1} \mathrm{~L}^{-1}$. After four feedings, the biomass was already exhausted and polysaccharide production was reduced.

Comparing fed batch results to the batch run, with $\mathrm{Px}=0.095 \mathrm{~g} \mathrm{~g}^{-1} \mathrm{~L}^{-1}, \mathrm{Pi}=0.078 \mathrm{~g} \mathrm{~g}^{-1} \mathrm{~L}^{-1}$ at $\mathrm{Pi} / \mathrm{x}$ $=33 \%$ and extracellular polysaccharides $\mathrm{Pe}=$ $0.095 \mathrm{~g} \mathrm{~g}^{-1} \mathrm{~L}^{-1}$ at $\mathrm{Pe} / \mathrm{x}=6.8 \%$, for the best production of $G$. lucidum fungal biomass and polysaccharides, $210 \mathrm{~h}$ of batch cultivation is proposed. According to the process optimization, shorter cultivation time also means lower energy consumption.

\section{References}

1. Jong, S. C., Birmingham, J. M., Medicinal benefits of the mushroom Ganoderma, Adv. Appl. Microbiol. 37 (1992) 101.

doi: https://doi.org/10.1016/S0065-2164(08)70253-3

2. Cör, D., Knez, Ž., Knez Hrnčič, M., Antitumour, antimicrobial, antioxidant and antiacetylcholinesterase effect of Ganoderma lucidum terpenoids and polysaccharides: A Review, Molecules 23 (3) (2018) 649.

doi: https://doi.org/10.3390/molecules23030649

3. Boh, B., Berovic, M., Zhang, J., Lin, Z.-B., Ganoderma lucidum and its pharmaceutically active compounds, Biotechnol. Annu. Rev. 13 (2007) 265. doi: https://doi.org/10.1016/S1387-2656(07)13010-6

4. Tasaka, K., Akagi, M., Miyoshi, K., Mio, M., Makino, T., Antiallergic constituents in the culture medium of Ganoderma lucidum. (I) Inhibitory effect of cyclooctasulfur on histamine release, Agents Actions 23 (1988) 153. doi: https://doi.org/10.1007/BF02142526

5. Van der Hem, L. G., van der Vliet, J. A., Bocken, C. F., Kino, K., Hoitsma, A. J., Tax W. J., Ling Zhi-8: Studies of a new immunomodulating agent, Transplantation 60 (1995) 438.

doi: https://doi.org/10.1097/00007890-199509000-00006

6. Maruyama, H., Yamazaki, K., Murofushi, S., Konda, C., Ikekawa, T., Antitumor activity of Sarcodon aspratus (Berk.) S. Ito and Ganoderma lucidum (Fr.) Karst, J. Pharmacobiodyn. 12 (1989) 118. doi: https://doi.org/10.1248/bpb1978.12.118

7. Lee, S. Y., Rhee, H. M., Cardiovascular effects of mycelium extract of Ganoderma lucidum: Inhibition of sympathetic outflow as a mechanism of its hypotensive action, Chem. Pharm. Bull. 38 (1990) 1359. doi: https://doi.org/10.1248/cpb.38.1359

8. Liu, G. T., Bao, T. T., Wei, H. L., Song, Z. Y., Some pharmacological actions of Ganoderma lucidum and Ganoderma japonicum on mouse liver, Acta Pharm. Sin. 14 (1979) 284.

9. Mizushina, Y., Takahashi, N., Hanashina, L., Koshino, H., Esumi, Y., Uzawa, J., Sugawara, F., Sakaguchi, K., Lucidenic acid $\mathrm{O}$ and lactone, new terpentene inhibitors of eukarytotic DNA polymerases from basidiomycete, Ganoderma lucidum, Bioorgan. Med. Chem. 7 (1999) 2047. doi: https://doi.org/10.1016/S0968-0896(99)00121-2

10. Yun, T. K., Update from Asia: Asian studies on cancer chemoprevention, Ann. New York Acad. Sci. 889 (1999) 157. doi: https://doi.org/10.1111/j.1749-6632.1999.tb08734.x

11. Kim, H. S., Kacew, S., Lee, M. B., In vitro chemo preventive effect of plant polysaccharides Aloe barbadensis Miller, Lentinus edodes, Ganoderma lucidum and Coriolus versicolor, Carcinogen. 20 (1999) 1637. doi: https://doi.org/10.1093/carcin/20.8.1637

12. Berovic, M., Habijanic, J., Zore, I., Wraber, B., Hodzar, D., Boh, B., Pohleven, F., Submerged cultivation of Ganoderma lucidum biomass and immunostimulatory effects of fungal polysaccharides, J. Biotech. 103 (2003) 77. doi: https://doi.org/10.1016/S0168-1656(03)00069-5

13. Zhang, W. X., Zhong, J. J., Effect of oxygen concentration in gas phase on sporulation and individual ganoderic acids accumulation in liquid static culture of Ganoderma lucidum, J. Biosci. Bioeng. 109 (2010) 37. doi: https://doi.org/10.1016/j.jbiosc.2009.06.024

14. Zhang, J., Zhong, J. J., Geng, A., Improvement of ganoderic acid production by cultivation of Ganoderma lucidum with cellulase as an elicitor, Process Biochem. 49 (2014) 1580 .

doi: https://doi.org/10.1016/j.procbio.2014.06.018 
15. Papinutti, L., Effects of nutrients, $\mathrm{pH}$ and water potential on exopolysaccharides production by a fungal strain belonging to Ganoderma lucidum complex, Bioresource Technol. 101 (2010) 1941.

doi: https://doi.org/10.1016/j.biortech.2009.09.076

16. Mizuno, T., Wang, G., Zhang, J., Kawagishi, H., Nishitoba, T., Li, J., Reishi, Ganoderma lucidum and Ganoderma tsugae: Bioactive substance and medicinal effects, Food Rev. Int. 11 (1995) 151. doi: https://doi.org/10.1080/87559129509541025

17. Miyahara, R., Yoshimoto, T., Asawa, K., Chemical structures and changes of extracts during growth of Reishi (Ganoderma lucidum), Mokuzai Gakkaishi 33 (1987) 416.

18. Chan, K., Linking Chemical and Biological Characteristics in Assuring the Quality of Chinese Medicinal Materials and OTC Products. In Lin, Z. B. (Ed.), Ganoderma: Genetics, chemistry, pharmacology and therapeutics, Proceedings of International symposium on Ganoderma research (Shanghai, China), Beijing Medical University Press, 2002, pp. 24-34.

19. Elisashvili, V., Submerged cultivation of medicinal mushrooms: Bioprocesses and products (Review), Int. J. Med. Mushrooms 14 (2012) 211. doi: https://doi.org/10.1615/IntJMedMushr.v14.i3.10

20. Yang, F. C., Liau, C. B., The influence of environmental conditions on polysaccharide formation by Ganoderma lucidum in submerged cultures, Proc. Biochem. 33 (1998) 547.

doi: https://doi.org/10.1016/S0032-9592(98)00023-5

21. Fang, Q. H., Zhong, J. J., Effect of initial $\mathrm{pH}$ on production of ganoderic acid and polysaccharide by submerged fermentation of Ganoderma lucidum, Proc. Biochem. 37 (2002) 769 . doi: https://doi.org/10.1016/S0032-9592(01)00278-3

22. Fang, Q. H., Zhong, J. J., Submerged fermentation of higher fungus Ganoderma lucidum for production of valuable bioactive metabolites - ganoderic acid and polysaccharide, Biochem. Eng. J. 10 (2002) 61. doi: https://doi.org/10.1016/S1369-703X(01)00158-9

23. Tang, Y. J., Zhong, J. J., Fed-batch fermentation of Ganoderma lucidum for hyperproduction of polysaccharide and ganoderic acid, Enz. Microb. Technol. 31 (2002) 20. doi: https://doi.org/10.1016/S0141-0229(02)00066-2
24. Tang, Y. J., Zhang, W., Zhong, J. J., Performance analyses of a pH-shift and DOT-shift integrated fed-batch fermentation process for the production of ganoderic acid and Ganoderma polysaccharides by medicinal mushroom Ganoderma lucidum, Biores. Technol. 100 (2009) 1852. doi: https://doi.org/10.1016/j.biortech.2008.10.005

25. Tang, Y. J., Zhang, W., Zhu, L. W., Hyperproduction of Ganoderma polysaccharides and ganoderic acid during fermentation of medicinal mushroom Ganoderma lucidum by multi-stage control and induced culture, J. Biosc. Bioeng. 108 (2009) 114 doi: https://doi.org/10.1016/j.jbiosc.2009.08.345

26. Fang, Q. H., Tang, Y. J., Zhong, J. J., Significance of inoculation density control in production of polysaccharide and ganoderic acid by submerged culture of Ganoderma lucidum, Proc. Biochem. 37 (2002) 1375. doi: https://doi.org/10.1016/S0032-9592(02)00017-1

27. Yang, F. C., Ke, Y. F., Kuo, S. S., Effect of fatty acids on the mycelial growth and polysaccharide formation by Ganoderma lucidum in shake-flask cultures, Enz. Mic. Technol. 27 (2000) 295. doi: https://doi.org/10.1016/S0141-0229(00)00213-1

28. Zhu, L. W., Zhong, J. J., Tang, Y. J., Multi-fed batch culture integrated with three-stage light irradiation and multiple additions of copper ions for hyperproduction of ganoderic acid and Ganoderma polysaccharides by the medicinal mushroom Ganoderma lucidum, Proc. Biochem. 45 (2010) 1904. doi: https://doi.org/10.1016/j.procbio.2010.03.010

29. Bandyopadyay, B., Humphrey, A. E., Taguchi, H., Dynamic measurement of the volumetric oxygen transfer coefficients in fermentation systems, Biotechnol. Bioeng. 9 (1967) 533. doi: https://doi.org/10.1002/bit.260090408

30. Dang, N. D. P., Karrer, D., Dunn, I. J., Oxygen transfer coefficient by dynamic model moment analysis, Biotechnol. Bioeng. 19 (1977) 853. doi: https://doi.org/10.1002/bit.260190606

31. Blanch, H. W., Bhavaraju, S. M., Non-Newtonian fermentation broths: Rheology and mass transfer, Biotechnol. Bioeng. 28 (1976) 745. doi: https://doi.org/10.1002/bit.260180602

32. Hsieh, C., Tseng, M. H., Liu, C. J., Production of polysaccharides from Ganoderma lucidum (CCRC 36041) under limitations of nutrients and oxygen, Enz. Microb. Technol. 38 (2006) 109. doi: https://doi.org/10.1016/j.enzmictec.2005.05.004 